\author{
U.S. DEPARTMENT OF HEALTH, EDUCRTION, AND WELFARE \\ CENTER FOR DISEASE CONTROL \\ NATIONAL INSTITUTE FOR OCCUPATIONAL SAFETY AND HEALTH \\ CINCINNATI, OHIO 45202 \\ HEALTH HAZARD EVALUATION DETERMINATION \\ REPORT NO. 74-715-204 \\ DIAMOND INTERNATIONAL CORPORATION \\ DIXFIELD, MAINE \\ JUNE 1975
}

I. TOXICITY DETERMINATION

It has been determined that lint and nuisance particulate in the cotton swab department at Diamond International Corporation, Diamond Match Division, Dixfield, Maine do not present a health hazard.

This determination is based on review of literature, environmental samples collected March 12-13, 1975, and review of medical questionnaires administered during the environmental sampling.

II. DISTRIBUTION AND AVAILABILITY OF DETERMINATION REPORT

Copies of this Determination Report are available upon request from the Hazard Evaluation Services Branch, NIOSH, U.S. Post Office Buila'ing, Room 508, 5th and Wainut Streets, Cincinnati, Ohio 45202. Copies have been sent to:
a) Diamond International Corporation (Diamond Match Division) Dixfield, Maine
b) Authorized Representative of Employees
c) U.S. Department of Labor - Region I, Boston, Mass.
d) NIOSH - Region I, Boston, Mass.

For the purposes of informing the approximately 14 "affected employees", the employer shall promptly "post" the Determination Report in a prominent place(s) near where exposed employees work for a period of 30 calendar days.

III. INTRODUCTION

Section 20(a)(6) of the Occupational Safety and Health Act of 1970 , 29 U.S.C. 669(a)(6), authorizes the Secretary of Health, Education, and Welfare, following a written request by any employer or authorized representative of employees, to determine whether any substance normally found in the piace of employment has potentially toxic effects in such concentrations as used or found. 
Page 2 - Health Hazard Evaluation Determination 74-115

The National Institute for Occupational Safety and Heaith (NIOSH) received such a request from an authorized representative of employees regarding exposure to "cotton dust" in the Cotton Swab Department at Diamond International Corporation, Diamond Match Division, Dixfield, Maine.

\section{HEALTH HAZARD EVALUATION}

\section{A. Plant Process - Conditions of Use}

The Dixfield, Maine facility is engaged in the manufacture of a variety of wood products and cotton swabs.

Cotton swabs are produced at a rate of 750 swabs/min./cotton swab machine (C.S.M.).

The entire cotton swab department is housed in one room ( $64^{\prime} \times 50^{\prime}$ ) with relatively high ceilings. In this room there are nine C.S.M.'s, one tray forming machine, one "cello-wrap" machine, two "blister sealers", and a "shrink tunnel."

Eight of the C.S.M.'s are operable with the ninth being installed. These eight machines are arranged in two groups of four. The cotton swabs produced by four of these C.S.M.'s are packaged in boxes, whereas those produced by the other four are "blister" packaged.

Machines number nine and ten have been equipped with a local exhaust system; this consists of a plexi-glass housing at the tearing and tipping point, flexible duct work, and a large industrial type vacuum cleaner. In addition to the local exhaust system, two ceiling units have been installed for the purpose of tempering and filtering the air. These units take in room air on the backside, filter and temper it, and then force it past a humidifier as it reenters the room. The humidifiers are separate units positioned just in front of each ceiling unit.

The actual production of cotton swabs is completely automated. Assuming no mechanical breakdown, the only requirement is that materials be supplied to the machines. An indexer (C.S.M. operator) is required to package the finished product at the production end of the machine.

Two 15 pound coils of clean processed cotton are threaded at one end of each C.S.M. This cotton is then applied to the paper sticks introduced from the hopper on top of each machine. The sticks are automatically fed (in the horizontal position) to a large rotating wheel. Each stick drops into a separate slot where it receives a glue application. The glue contained in a rectangular tray is applied to both ends of the stick by a second (smal1) wheel as the stick rotates past. Cotton is then applied to each end of the stick at the tearing and tipping point. The swabs are 
then sterilized by spraying a solution (contains small quantities of methyl cellosolve and phenylmercury acetate) at very close range; there is no overspray or noticeable odors.

During this survey four of the C.S.M.'s were being used; employees judged the production rate to be typical of any workday. The remaining equipment is used very intermittently.

The tray forming machine is used for very short periods of time and is completely automated.

One of the "blister sealers" was used by one employee throughout the day. Blister sealing consists of sealing cotton swabs in a plastic bubble with a cardboard backing; the sealer is held at a temperature of approximately $230^{\circ} \mathrm{F}$.

The "cello-wrap" machine and the "shrink tunnel", used for wrapping the cotton swabs packaged in cardboard trays, are also used very intermittently. "Cello-wrapping" consists of wrapping a sleeved box (contains 2-ninety count trays) with cellophane and then applying heat to it $\left(230^{\circ} \mathrm{F}\right.$.) in order to shrink the cellophane. The process is almost entirely automated; requiring an attendant to periodically load the machine with materials and remove the wrapped boxes. The individually wrapped boxes are then wrapped (six to a package) by utilizing the "shrink tunnel." The "shrinktunnel" operates on the same principle as the cello-wrap; the temperature is also the same.

There are normally twelve employees in the cotton swab department, which operates on day shift only. Their job classifications are: blister sealer (1), mechanics (2), machine tenders (2), indexers (4), sleeve inserter (1), packer (1), and utility person (1). Respectively, their job consists of: 1) sealing cotton swabs in a plastic bubble as described above, 2) repairing the equipment in the cotton swab department, 3) supplying materials to the C.S.M. 's and making minor adjustments on them, 4) packaging the cotton swabs in tray, ninety swabs per tray, 5) sleeving (packaging) the trays, two per sleeve, 6) wrapping sleeved trays while utilizing the cello-wrap machine, and then packaging them with the shrinktunnel, and 7) general clean up.

B. Evaluation Design and Methods

The alleged hazard was exposure to "cotton dust"; however, the lint and dust generated at the tipping and tearing point does not meet the definition of cotton dust as defined in NIOSH's criteria document, "Occupational Exposure to Cotton Dust." For this reason the sampling was for cotton lint and nuisance particulate and not cotton dust. 
Thirteen breathing zone samples and six area samples were collected during the two day sampling period. The breathing zone samples collected were for total dust (lint and nuisance particulate). Since the aerodynamic characteristics of lint are such that a cyclone may not be suitable for collecting the respirable fraction, four of the area samples were collected by using a vertical elutriator. This was done in an attempt to approximate the respirable fraction; the author recognizes that the upper cut-off limits are different (for cyclone and vertical elutriators).

In additon to collecting environmental samples, a medical questionnaire was administered to employees in the cotton swab department. The questionnaire is non directed; however, some directed questions were added in an attempt to detect any respiratory problems.

\section{Evaluation Criteria}

The samples collected were compared to the Federal nuisance dust standards; $5 \mathrm{mg} / \mathrm{M}^{3}$ for respirable fraction and $15 \mathrm{mg} / \mathrm{M}^{3}$ for total dust. The Federal Standard for raw cotton dust $\left(1 \mathrm{mg} / \mathrm{M}^{3}\right)$ is not applicable because of the reasons stated earlier.

While administering the medical questionnaires, particular attention was given to any symptoms which may be indicative of respiratory problem, such as, cough, coughing up phlegm, shortness of breath, chest tightness, and chest pains.

\section{Evaluation Results and Discussion}

All breathing zone and area samples were well below the nuisance dust standards (see Table I). The highest breathing zone concentration determined was $0.98 \mathrm{mg} / \mathrm{M}^{3}$ and the highest area sample concentration determined was $0.29 \mathrm{mg} / \mathrm{M}^{3}$. The concentrations determined for the four area samples collected with the vertical elutriator ranged from $0.04 \mathrm{mg} / \mathrm{M}^{3}$ to $0.13 \mathrm{mg} / \mathrm{m}^{3}$.

Not only were all samples collected well below the nuisance dust standards, but they were also below the standard for raw cotton dust, had it been applicable.

According to the Medical Services Branch Chief, "review of the medical questionnaires did not provide significant evidence that workers were having respiratory problems associated with their work environment."

For these reasons it was determined that a health hazard due to nuisance dust in the cotton swab department of Diamond International's Dixfield, Maine facility does not exist. 
Page 5 - Health Hazard Evaluation Determination 74-115

V. REFERENCES

1. Occupational Exposure to Cotton Dust, U.S. Department of Health, Education, and Welfare; Public Health Service; Center for Disease Control, National Institute for Occupational Safety and Health.

VI. AUTHORSHIP AND ACKNOWLEDGMENTS

Report Prepared By:

Raymond 0. Rivera, Industrial Hygienist

Hazard Evaluation Services Branch

Cincinnati, Ohio

Originating Office: Jerome P. Flesch, Chief

Hazard Evaluation Services Branch

Cincinnati, Ohio

Acknowledgments

John R. Kominisky

Industrial Hygienist

Hazard Evaluation Services Branch

Cincinnati, Ohio

Robert N. Ligo, M.D.

Chief, Medical Services Branch

Cincinnati, Ohio 
TABLE I

AIR SAMPLE RESULTS OF NUISANCE DUST

March 12-13, 1975

\begin{tabular}{|c|c|c|c|c|c|}
\hline Sample \# & Job Classification & Time & Date & $\begin{array}{l}\text { Concentration } \\
\text { in } \mathrm{mg} / \mathrm{M}^{3} \\
\end{array}$ & Comments \\
\hline$V-50$ & Indexer & $1207-1459$ & $03 / 12 / 75$ & 0.29 & On C.S.M. \#1 \\
\hline$V-49$ & Indexer & $1211-1459$ & $03 / 12 / 75$ & 0.15 & on C.S.M. \#3 \\
\hline$V-43$ & Indexer & $1216-1459$ & $03 / 12 / 75$ & $<0.15$ & On C.S.M. \#9 \\
\hline$V-39$ & Indexer & $1215-1459$ & $03 / 12 / 75$ & 0.98 & On C.S.M. \#10 \\
\hline$V-30$ & Machine tender & $1219-1459$ & $03 / 12 / 75$ & $<0.15$ & On C.S.M. \#9 \& \#10 \\
\hline$V-47$ & $\begin{array}{l}\text { Gen. Area of C.S.M.'s } \\
1 \& 3\end{array}$ & $1225-1459$ & $03 / 12 / 75$ & 0.29 & \\
\hline$V-42$ & $\begin{array}{l}\text { Gen. Area of C.S.M.'s } \\
9 \& 10\end{array}$ & $1229-1459$ & $03 / 12 / 75$ & $<0.17$ & \\
\hline$V-48$ & $\begin{array}{l}\text { Gen. Area of C.S.M. of } \\
\# 9 ; \approx 5 \text {, away }\end{array}$ & $1136-1505$ & $03 / 12 / 75$ & 0.04 & $\begin{array}{l}\text { Elutriator used; no activity during } 1 / 2 \mathrm{hr} \text {. lunch } \\
\text { (approximates respirable fraction) }\end{array}$ \\
\hline$V-44$ & $\begin{array}{l}\text { Gen. Area; between } \\
\text { Cello-wrap machine \& } \\
\text { Quality Control Inspector }\end{array}$ & $\begin{array}{r}1130-1500 \\
r\end{array}$ & $03 / 12 / 75$ & 0.09 & $\begin{array}{l}\text { Elutriator used; no activity during lunch } \\
\text { (approximates respirable fraction) }\end{array}$ \\
\hline$V-46$ & Machine Tender & $0706-1450$ & $03 / 13 / 75$ & 0.46 & on C.S.M.'s \#1 \& \#3 \\
\hline$V-41$ & Indexer & $0708-1450$ & $03 / 13 / 75$ & 0.15 & On C.S.M. \#3 \\
\hline$V-36$ & Indexer & $0712-1450$ & $03 / 13 / 75$ & 0.26 & on C.S.M. \#1 \\
\hline$v-22$ & Indexer & $0737-1450$ & $03 / 13 / 75$ & 0.12 & On C.S.M. \#10 \\
\hline$V-11$ & Machine Tender & $0740-1450$ & $03 / 13 / 75$ & 0.31 & On C.S.M.'s \#9 \& \#10 \\
\hline$V-21$ & Indexer & $0744-1450$ & $03 / 13 / 75$ & 0.14 & On C.S.M. \#g \\
\hline$V-16$ & Mechanic & $0747-1450$ & $03 / 13 / 75$ & 0.19 & \\
\hline$v-6$ & Mechanic & $0750-1450$ & $03 / 13 / 75$ & 0.17 & \\
\hline$V-17$ & Gen. Area & $1134-1500$ & $03 / 13 / 75$ & 0.13 & $\begin{array}{l}\text { Elutriator used; no activity during } 1 / 2 \mathrm{hr} \text {. Iunch } \\
\text { (approximates respirable fraction) }\end{array}$ \\
\hline$y-12$ & Gen. Area & $1139-1500$ & $03 / 13 / 75$ & 0.09 & $\begin{array}{l}\text { Elutriator used; no activity during } 1 / 2 \mathrm{hr} \text {. lunch } \\
\text { (approximates respirable fraction) }\end{array}$ \\
\hline
\end{tabular}

